\title{
O USO DE SEQUÊNCIAS E PADRÕES PARA O DESENVOLVIMENTO DO PENSAMENTO ALGÉBRICO NOS ANOS INICIAIS DO ENSINO FUNDAMENTAL
}

\author{
Rejane Bianchini \\ Marli Teresinha Quartieri
}

\begin{abstract}
Resumo: As reflexóes suscitadas pela aprovação da Base Nacional Comum Curricular (BRASIL, 2017), as inquietaçóes e as discussóes ao longo do Curso de Pós-Graduaçáo na área de Ensino de Ciências Exatas originaram o presente trabalho. Este discorre sobre uma pesquisa de abordagem qualitativa que teve o intuito de refletir sobre o uso de sequências e padrôes para o desenvolvimento do pensamento algébrico nos Anos Iniciais do Ensino Fundamental. Dentro desta proposta, organizouse e aplicou-se uma sequência de atividades envolvendo sequências e padróes para a promoção do pensamento algébrico em uma turma aglutinada dos Anos Iniciais de uma escola da rede pública do Vale do Taquari/RS. A turma de aplicação estava composta por alunos do $2^{\circ}$ e $3^{\circ}$ anos, com faixa etária entre 7 e 10 anos. Esta proposta esteve permeada pelas concepçóes de Van de Walle (2009) e Mestre (2014) sobre pensamento algébrico e de Boaler (2018) sobre atividades e currículo. No decorrer das atividades realizou-se debates em grupos, que foram registrados através de fotos, de escritos e de anotaçóes no Diário de Campo da pesquisadora. Da análise desses dados, foi possível identificar que o trabalho desenvolvido contribuiu para que os alunos desta pesquisa desenvolvessem conceitos do pensamento algébrico, tais como: noção de sequência repetitiva, relaçóes recursivas e funcionais.
\end{abstract}

Palavras-chave: Padróes e sequências. Pensamento Algébrico. Anos Iniciais.

\section{THE USE OF SEQUENCES AND STANDARDS FOR THE DEVELOPMENT OF ALGEBRAIC THINKING IN THE EARLY YEARS OF ELEMENTARY SCHOOL}

\begin{abstract}
The reflections aroused by the approval of the Common National Curriculum Base (BRAZIL, 2017), the concerns and the discussions during the Graduate Course in Exact Science Teaching have originated the present work. This paper discusses about a research with a qualitative approach that aimed to reflect on the use of sequences and standards for the development of algebraic thinking in the early years of elementary school. Within this proposal, it was organized and applied a set of activities involving sequences and standards for the promotion of algebraic thinking in an agglutinated Early-Year class from a public school in Vale do Taquari/ RS. The application class was
\end{abstract}


composed of students from the $2^{\text {nd }}$ and $3^{\text {rd }}$ grades, aged between 7 and 10 years. This proposal has been permeated by Van de Walle (2009) and Mestre (2014) about algebraic thinking and Boaler (2018) about activities and curriculum. Throughout the activities, discussions took place in groups, which were recorded through photos, writings and notes on the researcher's Field Journal. From the analysis of these data, it was possible to identify that the performed work contributed for the students of this research to develop concepts of algebraic thinking, such as: notion of repetitive sequence, recursive and functional relations.

Keywords: Standards and sequences. Algebraic thinking. Early years.

\section{Consideraçóes Iniciais}

Ao longo da história da educação, o ensino de matemática vem sendo discutido por diversos autores, que alicerçados em seus estudos, mediatizaram diferentes tendências para a potencialização desta área de ensino. Estas tendências, por sua vez, influenciaram as reformas curriculares para o ensino. No que diz respeito ao nosso país, este debate se intensificou em especial nos últimos anos. Basta lembrarmos das determinações da Lei de Diretrizes e Bases da Educação (BRASIL, 2018), aprovada em 1996, que previa por exemplo no seu artigo 26, uma base nacional comum que concomitou com a organização dos Parâmetros Curriculares Nacionais (BRASIL, 1997). Estes últimos, por seu lado, ressaltaram no currículo dos Anos Iniciais do Ensino Fundamental algumas orientações sobre o ensino de matemática, a citar por exemplo, o "recurso à resolução de problemas", o "recurso à história da matemática" e o "recurso às tecnologias da informação". Já no final de 2017, dando continuidade a estas discussões e visando potencializar o ensino, foi aprovada a Base Nacional Comum Curricular (BNCC). A aprovação da BNCC (BRASIL, 2017), por ser recente, tem suscitado discussões sobre os rumos que a educação tomará no Brasil, a partir deste documento.

Desta forma, considerando-se a complexidade e amplitude do debate que historicamente se estabelece no país e a dificuldade de abordá-lo, optou-se pela realização de um recorte dessas discussões. Dadas essas condições, o presente trabalho pretende discutir sobre "Que implicações o uso de sequências e padrões tem para o desenvolvimento do pensamento algébrico nos alunos dos Anos Iniciais do Ensino Fundamental?". E na tentativa de encaminhar respostas a essa discussão, foram traçados os seguintes objetivos: enumerar as hipóteses utilizadas pelos estudantes para analisar sequências e seus padrões; investigar a relação destas conjecturas com o desenvolvimento do pensamento algébrico; analisar que implicações a realização de um conjunto de atividades envolvendo sequências/ padrões tem para a promoção do pensamento algébrico em alunos de diferentes níveis de escolarização e refletir sobre as intervenções realizadas pela pesquisadora no decorrer da execução deste conjunto de atividades.

Para tal tratativa, realizou-se uma pesquisa, de abordagem qualitativa, na qual foi organizada e desenvolvida uma série de atividades sobre sequências e padrões para a promoção do pensamento algébrico nos Anos Iniciais do Ensino Fundamental. Tais estudos emergiram das orientações da BNCC (BRASIL, 2017), 
das considerações de Van de Walle (2009) e Mestre (2014) sobre pensamento algébrico e das ideias de currículo e atividades de Boaler (2018).

Assim, o presente estudo apresenta em seu item 2, as concepções teóricas que basilaram as concepções de currículo e de pensamento algébrico nos Anos Iniciais. O item 3, contextualiza o trabalho e explana sobre a metodologia utilizada. Realizam-se as discussões dos desdobramentos deste trabalho à luz das concepções teóricas no item 4; e, finaliza-se no item 5, apresentando os resultados deste processo de intervenção.

\section{Concepçóes Teóricas}

A proposta do estudo de álgebra nos Anos Iniciais do Ensino Fundamental, explanada pela BNCC (BRASIL, 2017), tem gerado diálogos entre o grupo de professores. Estes diálogos, nem sempre permeiam o nível da tranquilidade e da clareza acerca desta temática. Sabe-se, pela atualidade deste documento, que essa discussão é recente em nosso país. No entanto, se uma leitura detalhada dos Parâmetros Curriculares Nacionais de Matemática, que datam de 1997, for realizada, verificar-se-á que aquele documento já fazia referências ao estudo de álgebra no Ensino Fundamental, ao abordar a seleção de conteúdos e afirmar que:

Há um razoável consenso no sentido de que os currículos de Matemática para o ensino fundamental devam contemplar o estudo dos números e das operações (no campo da Aritmética e da Álgebra), o estudo do espaço e das formas (no campo da Geometria) e o estudo das grandezas e das medidas (que permite interligações entre os campos da Aritmética, da Álgebra e da Geometria) (BRASIL, 1997, p. 38, grifo nosso).

Este mesmo documento, enfatizava o estudo de álgebra nos Anos Finais do Ensino Fundamental, ao afirmar que "Embora nas séries iniciais já se possa desenvolver uma pré-álgebra, é especialmente nas séries finais do ensino fundamental que os trabalhos algébricos serão ampliados" (BRASIL, 1997, p. 39). No entanto, o próprio documento, já fazia indicativos da importância do trabalho com álgebra (pré-álgebra) já nos Anos Iniciais do Ensino Fundamental, ao apontar, por exemplo, no primeiro ciclo, objetivos como:

Interpretar e produzir escritas numéricas, levantando hipóteses sobre elas, com base na observação de regularidades, utilizando-se da linguagem oral, de registros informais e da linguagem matemática [...] Desenvolver procedimentos de cálculo - mental, escrito, exato, aproximado - pela observação de regularidades e de propriedades das operações e pela antecipação e verificação de resultados (BRASIL, 1997, p. 47, grifo nosso).

Ou ao descrever nos conteúdos conceituais e procedimentais do primeiro ciclo, a importância da

- Observação de critérios que definem uma classificação de números (maior que, menor que, estar entre) e de regras usadas em seriações (mais 1, mais 2, dobro, metade). 
- Contagem em escalas ascendentes e descendentes de um em um, de dois em dois, de cinco em cinco, de dez em dez, etc., a partir de qualquer número dado.

- Identificação de regularidades na série numérica para nomear, ler e escrever números menos frequentes (BRASIL, 1997, p. 50).

Estas mesmas referências à álgebra citadas nos PCNs (BRASIL, 1997), são identificáveis no atual documento de referência do país, a BNCC (BRASIL, 2017), ao apresentar os objetos de conhecimento e as habilidades a serem desenvolvidas em cada ano de escolaridade do Ensino Fundamental. Por exemplo, para o segundo ano do Ensino Fundamental, a BNCC (BRASIL, 2017, p. 280) aponta como objeto de conhecimento a "Construção de sequências repetitivas e de sequências recursivas" e "Identificação de regularidade de sequências e determinação de elementos ausentes na sequência" e como habilidades a serem desenvolvidas para estes objetos de conhecimento, relaciona:

Descrever um padrão (ou regularidade) de sequências repetitivas e de sequências recursivas, por meio de palavras, símbolos ou desenhos. [...] Descrever os elementos ausentes em sequências repetitivas e em sequências recursivas de números naturais, objetos ou figuras (BRASIL, 2017, p. 281).

Ou ainda, para o terceiro ano, destaca como objeto de conhecimento: "Identificação e descrição de regularidades em sequências numéricas recursivas" e "Relação de igualdade" (BRASIL, 2017, p. 284). Como habilidades a serem desenvolvidas para os mesmos:

Identificar regularidades em sequências ordenadas de números naturais, resultantes da realização de adições ou subtrações sucessivas, por um mesmo número, descrever uma regra de formação da sequência e determinar elementos faltantes ou seguintes. [...] Compreender a ideia de igualdade para escrever diferentes sentenças de adições ou de subtrações de dois números naturais que resultem na mesma soma ou diferença (BRASIL, 2017, p. 285).

Todavia, a BNCC (BRASIL, 2017), diferentemente dos PCNs (BRASIL, 1997), destaca em seu texto, a importância do trabalho com álgebra ao apresentá-la como uma unidade temática a ser trabalhada em todo o Ensino Fundamental e ao afirmar que:

[...] é imprescindível que algumas dimensões do trabalho com a álgebra estejam presentes nos processos de ensino e aprendizagem desde o Ensino Fundamental - Anos Iniciais, como as ideias de regularidade, generalização de padrões e propriedades da igualdade. No entanto, nessa fase, não se propõe o uso de letras para expressar regularidades, por mais simples que sejam. A relação dessa unidade temática com a de Números é bastante evidente no trabalho com sequências (recursivas e repetitivas), seja na ação de completar uma sequência com elementos ausentes, seja na construção de sequências segundo uma determinada regra de formação (BRASIL, 2017, p. 268).

Fundamentando as ideias apresentadas pela BNCC (BRASIL, 2017), Van de Walle (2009) destaca a importância de um trabalho pedagógico intencional, que potencialize a capacidade de aprender a procurar padrões, descrevê-los, traduzi- 
los e ampliá-los, como um fazer matemático e do pensar algebricamente. Salienta ainda, que a exploração de repetições de padrões é um ponto de partida para os Anos Iniciais do Ensino Fundamental. Do mesmo modo, Mestre (2014) ratifica a importância de um trabalho pedagógico que contemple o estudo da álgebra já nos Anos Iniciais, ao discorrer em seus estudos que

O PMEB (ME, 2007) reconhece a importância da introdução do pensamento algébrico nos primeiros anos de escolaridade, em consonância com os resultados da investigação internacional, dos quais se destaca os estudos realizados no âmbito da Early Algebra. A abordagem Early Algebra promoveu uma nova visão da relação aritmética-álgebra, revelando o caráter algébrico da aritmética e questionando a prática corrente de ensinar primeiro aritmética e depois álgebra. São vários os estudos (e.g. Blanton \& Kaput, 2005; Carpenter, Franke \& Levi, 2003; Carraher et al., 2007; Fujii \& Stephens, 2008; Warren \& Cooper, 2005) que demostram como os alunos dos primeiros anos de escolaridade são capazes de pensar algebricamente (MESTRE, 2014, p. 11).

\section{Além disso, Boaler amplia a importância e a abrangência do desenvolvimento do pensamento algébrico, ao afirmar que}

A matemática é um fenômeno cultural; um conjunto de ideias, conexões e relações desenvolvidos para que as pessoas compreendam o mundo. Em sua essência, a matemática trata de padrões. Podemos colocar uma lente matemática sobre o mundo. E quando o fazemos, vemos padrões em toda parte; e é por meio de nossa compreensão dos padrões, desenvolvida mediante o estudo matemático, que se cria um novo e poderoso conhecimento (BOALER, 2018, p. 22).

Dessa forma, a autora defende a ideia de que "[...] o currículo é o melhor amigo do professor. Todo professor sabe que ótimas tarefas matemáticas constituem um recurso maravilhoso. Elas podem fazer a diferença entre estudantes inspirados e felizes e estudantes desmotivados e distantes" (BOALER, 2018, p. 51). Ao fazer essa afirmação, Boaler (2018) destaca a importância do planejamento do professor, no fazer matemática. Ainda segundo a referida autora, é importante oferecer aos alunos tarefas de "piso baixo" e "teto alto". Mas o que seriam essas tarefas? Conforme a autora, estas tarefas, seriam atividades que permitem uma ampla variedade de interpretações, que variam de níveis mais simples a níveis mais complexos, possibilitando que todos os alunos se envolvam com a mesma atividade, mas em níveis diferentes, de acordo com o seu desenvolvimento. Em efeito:

Tarefas de "piso baixo" e "teto alto" permitem que todos os alunos acessem ideias e as elevem a níveis altíssimos. Felizmente, tarefas de "piso baixo" e "teto alto" também são os exercícios matemáticos mais envolventes e interessantes pelo fato de funcionarem para estudantes de diferentes níveis de desempenho anterior. São tarefas que ensinam matemática relevante, inspiram interesse e encorajam a criatividade (BOALER, 2018, p. 103).

Contribuindo com estas ideias, Smole (2007, p. 11) afirma que

É por meio da troca de pontos de vista com outras pessoas que a criança progressivamente descentra-se, isto é, ela passa a pensar por uma outra 
perspectiva e, gradualmente, a coordenar seu próprio modo de ver com outras opiniões. Isso não vale apenas na infância, mas em qualquer fase da vida. Podemos mesmo afirmar que, sem a interação social, a lógica de uma pessoa não se desenvolveria plenamente, porque é nas situações interpessoais que ela se sente obrigada a ser coerente. Sozinha poderá dizer e fazer o que quiser pelo prazer e pela contingência do momento; porém em grupo, diante de outras pessoas, sentirá a necessidade de pensar naquilo que dirá, que fará, para que possa ser compreendida.

Portanto, a escolha de atividades levou em consideração as orientações da BNCC (BRASIL, 2017) sobre pensamento algébrico, que foram expandidas neste trabalho, por meio da inserção dos discursos de Van de Walle (2009) e Mestre (2014).

Isto posto, optou-se por assumir no desenvolvimento deste trabalho, a concepção de pensamento algébrico como um "processo em que os alunos generalizam ideias matemáticas a partir de um conjunto de exemplos particulares, estabelecem essa generalização através do discurso da argumentação, e expressamna gradualmente de uma forma simbólica apropriada à sua idade" (BLANTON e KAPUT, 2005, p. 413 apud MESTRE, 2014, p. 16). Entende-se, pois, que esta concepção algébrica, contempla as habilidades a serem atingidas nos Anos Iniciais do Ensino Fundamental, conforme orientações da BNCC (BRASIL, 2017). Além do mais, esta visão algébrica, permite o desenvolvimento de atividades de "piso baixo" e "teto alto", propostas por Boaler (2018) e estabeleceu os próximos passos do presente trabalho, descritos na sequência.

\section{Contexto da investigaçáo e procedimentos metodológicos}

Com base nos documentos oficiais indicados e na concepção de pensamento algébrico assumida no presente trabalho, organizou-se uma intervenção pedagógica de oito períodos, com cinquenta minutos cada. Esta proposta pedagógica foi aplicada em uma turma aglutinada dos Anos Iniciais do Ensino Fundamental de uma escola pública do Vale do Taquari. A presente turma estava organizada em um agrupamento de alunos que frequentavam o $2^{\circ}$ e $3^{\circ}$ anos do Ensino Fundamental. A turma do $2^{\circ}$ ano era composta por 7 estudantes, com faixa etária entre 7 e 8 anos, sendo destes, 4 do sexo feminino e 3 do sexo masculino. A turma do $3^{\circ}$ ano, por sua vez, era composta por 15 estudantes, com faixa etária entre 8 e 10 anos, 6 do sexo feminino e 9 do sexo masculino, sendo que um destes alunos estava evadido durante o período de aplicação das atividades. Desta forma, o coletivo de estudantes que participaram desta proposta foi composto por 22 indivíduos, com faixa etária entre 7 e 10 anos, que permaneciam na escola das 7 h30 às 16h30, de segunda-feira à sexta-feira, com intervalo para descanso ao meio dia.

O desenvolvimento destas atividades visava coletar dados para tentar responder as inquietações iniciais que originaram este trabalho e alavancar possibilidades de práticas pedagógicas que envolvessem a questão do pensamento algébrico já nos Anos Iniciais do Ensino Fundamental. Mediante o exposto, optou-se por uma abordagem qualitativa, por entender-se que o presente trabalho 
pretende refletir sobre a prática pedagógica, com vistas a sua qualificação, mediante planejamento prévio. Ademais,

A pesquisa qualitativa considera que há uma relação dinâmica, especial, contextual e temporal entre pesquisador e objeto de estudo; ambos pertencem à mesma realidade e se confundem. Por isso, a pesquisa qualitativa carece de que fenômenos sociais sejam interpretados à luz do contexto, do tempo, dos fatos e análise de todas as interferências. $\mathrm{O}$ ambiente da vida real é a fonte direta para obtenção dos dados, e a capacidade do pesquisador de interpretar essa realidade, com isenção e lógica, baseando-se em teoria existente, é fundamental para dar significado às respostas (MICHEL, 2015, p. 40).

Considerou-se ainda que "a pesquisa qualitativa se preocupa, portanto, com aspectos da realidade que não podem ser quantificados, centrando-se na compreensão e explicação da dinâmica das relações sociais" (GERHARDT; SILVEIRA, 2009, p.32). À vista disso, entende-se que esta metodologia se aproxima do propósito do presente trabalho, potencializando suas discussões. Junto a este cenário, fazem-se pertinentes também os instrumentos de coleta de dados. São eles que permitem à pesquisadora enumerar elementos para as suas reflexões e análises. Desta forma, elencaram-se para esta pesquisa os registros no Diário de Campo da pesquisadora, as fotos das atividades realizadas e os registros escritos dos alunos.

Os registros no Diário de Campo foram realizados após cada encontro. Eles contemplam a narrativa da pesquisadora: impressões, angústias e reflexões. Acolhem ainda, de forma sequencial, as fotos e as análises das respostas dadas pelos alunos durante o desenvolvimento das atividades. Desta forma, entende-se que eles corroboram e viabilizam o desenvolvimento do presente trabalho, pois permitem que o contexto, os fatos, as narrativas e o tempo tão pertinentes para a pesquisa de abordagem qualitativa citada por Michel (2015) estejam registrados, de forma organizada. Esta forma de registro potencializa a análise e interpretação de dados, sistematizada pela análise descritiva.

Estes dois processos, apesar de conceitualmente distintos, aparecem sempre
estritamente relacionados. A análise tem por objetivo organizar e sumariar os
dados de tal forma que possibilitem o fornecimento de respostas ao problema
proposto para a investigação. Já a interpretação tem como objetivo a procura
de sentido mais amplo das respostas, o que é feito mediante sua ligação a
outros conhecimentos anteriormente obtidos (GIL, 2012, p. 156).

Assim, após a análise e interpretação dos dados, descrevem-se, a seguir, as reflexões e considerações da análise descritiva, ancoradas nas premissas teóricas do campo algébrico, explanadas no capítulo 2 do presente texto.

\section{Uso de sequências e padróes por alunos de uma turma aglutinada do Ensino Fundamental}

Apresentar-se-á neste capítulo o desdobramento das atividades realizadas junto a turma aglutinada dos Anos Iniciais do Ensino Fundamental à luz das reflexões teóricas propostas neste trabalho. Estas foram desenvolvidas por meio 
de grupos de dois a quatro alunos, de interações orais (socialização de ideias nos pequenos grupos e no grande grupo) e escritas (considere-se aqui a inclusão de desenhos). A exploração das atividades tencionou investigar que implicações o uso de sequências e padrões tem para o desenvolvimento do pensamento algébrico nos alunos dos Anos Iniciais do Ensino Fundamental. Assim, foram realizadas as seguintes atividades: brincando de detetive, brincando com o Lego, brincando e aprendendo com sequências e sequências numéricas, relatadas a seguir.

\subsection{Brincando de Detetive}

A Brincadeira de Detetive, realizada durante as duas primeiras aulas, pretendia introduzir de forma lúdica a noção de sequência e padrão aos alunos, que segundo relato oral da professora da turma, ainda não haviam tido contato com essas terminologias e nem com esse tipo de atividade. A brincadeira se pautava na organização dos alunos em filas, obedecendo determinados critérios (os padrões das sequências), pré-estabelecidos pela aplicadora. Por exemplo: a primeira fila foi organizada com uma criança em pé, outra criança sentada, uma em pé, outra sentada... O aluno que era escolhido para ser o detetive, deveria "descobrir o segredo" (padrão) da organização da fila. Caso este não conseguisse, a turma deveria auxiliá-lo nesta tarefa. Em seguida, eram elencados questionamentos sobre como seriam colocadas as próximas pessoas da fila ou como seria a posição de determinada pessoa na fila, a partir do "segredo" desvendado.

Nesta intervenção, foi possível desenvolver quatro sugestões de organização de fila, que por sua vez, suscitaram diversas hipóteses e discussões entre os alunos. Entre os debates ocorridos, destaca-se o que aborda a questão dos números pares e ímpares (descrito, mais adiante, no Quadro 4), conceito não previsto inicialmente para discussão com a turma. Entendemos que esta situação é passível de ocorrer, uma vez que "pode sempre programar-se o modo de começar uma investigação matemática, mas nunca se sabe como ela irá acabar" (PONTE; BROCARDO; OLIVEIRA, 2003, p.25). Esta observação chama a atenção para a aproximação da situação de aprendizagem desenvolvida com a tendência de ensino de Ponte, Brocardo e Oliveira (2003) conhecida como investigação matemática.

Durante o desenrolar da brincadeira, foi possível observar, que as crianças foram se apropriando da noção de padrão que era estabelecida nas filas e tanto os alunos do segundo ano, como os do terceiro ano conseguiram "descrever um padrão (ou regularidade) de sequências repetitivas [...] por meio de palavras" (BRASIL, 2017, p. 281), conforme habilidade descrita na BNCC (BRASIL, 2017) a ser desenvolvida por alunos do segundo ano. Nos quadros 1 e 2, trechos do Diário de Campo da aplicadora, que validam essas ideias: 


\section{Quadro 1 - Brincando de Detetive - Trecho I.}

Ao organizarmos a primeira fila, utilizando como padrão uma criança em pé e outra sentada, a primeira criança que atuou como detetive demorou um pouco para responder o que estava observando na fila. Então, sugeri que o restante da turma auxiliasse. Algumas disseram que viam crianças, outras falavam em meninos e meninas... (isso, considerando que me viram organizar a fila, diferentemente do aluno que estava atuando como detetive e que ficou do lado de fora da sala, sem acesso a esta visualização). Então fui reformulando minha pergunta, questionando como as crianças estavam organizadas na fila. Daí rapidamente as crianças responderam que uma estava em pé e outra sentada. Questionei as crianças sobre qual seria o segredo da fila que o detetive deveria descobrir e elas me disseram que era esse. Isso me fez refletir, se a questão inicial estava bem elaborada para a compreensão das crianças.

Fonte: Diário de Campo (22 out. 2018).

\section{Quadro 2 - Brincando de Detetive - Trecho II.}

Em seguida, passamos para a fila 4: Uma criança de cabelo curto, uma criança de cabelo longo... Ao ser questionado sobre o que observavam na fila, a primeira criança que estava atuando como detetive tentou utilizar a hipótese anterior sobre gênero e disse: uma menina e um menino. Então, como tinha colocado duas meninas seguidas uma da outra, questionei se esta regra estava certa. A turma ficou na dúvida: Apontaram para onde elas estavam e disseram: "Até ali, sim profe! Depois mudou." Então questionei se a regra poderia mudar e os alunos ficaram na dúvida. Então questionei se poderia talvez ter outro segredo que não estavam identificando. As crianças ficaram pensando, caminharam ao redor da fila observando os colegas, apontavam para os colegas tentando identificar algo, mas como percebi que estavam com dificuldades, questionei: "O que está mudando do primeiro da fila para o segundo? E do segundo pro terceiro?” E fui insistindo nessa pergunta, até que uma menina disse: "O cabelo profe!!! Um é grande e o outro é pequeno!"

Fonte: Diário de Campo (22 out. 2018).

Infere-se desses trechos do Diário de Campo (Quadros 1 e 2) que durante a realização das atividades os alunos construíram relações recursivas. Ou seja, segundo Van de Walle (2009, p. 300), conseguiram descrever "como um padrão é modificado de um passo ao passo seguinte" Além da apropriação da noção de padrão e da construção de relações recursivas, as crianças também criaram hipóteses para descobrir um elemento ausente na sequência, como por exemplo, qual seria a posição da próxima pessoa na fila ou como seria a posição de determinada pessoa em determinado lugar da fila (por exemplo, no $15^{\circ}$ lugar da fila). No Quadro 3 temos um trecho do Diário de Campo para exemplificação: 
Quadro 3 - Brincando de Detetive - Trecho III.

Já ao serem questionadas sobre como deveria ser continuada a fila, as crianças rapidamente indicaram que a próxima criança deveria sentar, visto que a última que eu tinha organizado na fila estava em pé. Ao serem questionadas sobre como deveria ser colocada a $10^{\circ}$ criança na fila, as crianças chutaram suas respostas: em pé, sentada. Então questionei como poderíamos descobrir isso. Então alguns alunos sugeriram que montássemos a fila até chegar em 10 crianças e assim o fizemos. Em seguida, questionei como seria a posição da $15^{\mathrm{a}}$ criança e as crianças novamente sugeriram que continuássemos a montar a fila. Então eu questionei: "Vocês não tem uma ideia diferente, que a gente possa resolver isso sem ter que montar a fila?" Então a aluna F2, disse que seria em pé, pois o quinto aluno estava em pé, e que quinze era igual ao cinco". Solicitei a aluna que explicasse melhor sua ideia, ao passo que ela disse: "Profe, olha, o quinze termina com cinco, então eles são iguais. Então o quinze também será em pé." Em seguida, realizamos a sistematização desta fila no quadro e testamos a ideia da aluna, desenhando-a no quadro. Então verificamos que sua hipótese estava correta.

Fonte: Diário de Campo (22 out. 2018).

Por meio dessa atividade, percebeu-se que as crianças estavam desenvolvendo o pensamento algébrico, haja visto, que nesta situação construíram relações funcionais. As relações funcionais, segundo Van de Walle (2009, p. 300) são aquelas em que é criada "uma regra que determine o número de elementos em um passo a partir do número de passos". Além disso, acredita-se que as crianças estão desenvolvendo a habilidade de "Descrever os elementos ausentes em sequências repetitivas" (BRASIL, 2017, p. 281), conforme previsto pela BNCC (BRASIL, 2017) para o segundo ano. Aliás, percebe-se nesta narrativa, a iniciação das crianças na criação de conjecturas, ressaltando a importância de o professor atuar como mediador do processo, realizando interferências que permitam o avanço dos alunos em suas hipóteses, conforme defendido por Ponte, Brocardo e Oliveira (2003). Outra situação, que vem corroborar com a situação exposta, encontra-se no Quadro 4, onde as crianças, com auxílio da pesquisadora, conseguiram relacionar o comprimento do cabelo na sequência elaborada a condição de ser um número par ou um número ímpar. 


\section{Quadro 4 - Brincando de Detetive - Trecho IV.}

Em seguida ao serem questionados de como seria o cabelo da $50^{\mathrm{a}}$ pessoa da fila, a aluna F2 disse que seria curto, pois a $5^{\circ}$ pessoa da fila tinha cabelo curto, demonstrando que estava novamente tentando utilizar a hipótese da fila anterior e que não tinha compreendido a explicação dada anteriormente. Já o aluno L3, disse que era longo. Então questionei como sabia disso, ao passo que me respondeu que o $10^{\circ}$ da fila tinha cabelo longo e que contando de $10 \mathrm{em} 10$, até o 50 , o $50^{\circ}$ teria cabelo longo. C2, por sua vez, disse que chegou a resposta (cabelo curto), contando de 5 em 5. Então questionei se ele tinha certeza da sua resposta e ele insistiu que sim, reforçando sua hipótese: "Olha, profe, o $5^{\circ}$ tem cabelo curto, daí conta de 5 em 5, e o 50 também tem cabelo curto." Então como a turma não chegou num acordo sobre a comprimento do cabelo da $50^{\mathrm{a}}$ pessoa da fila, sugeri aos alunos que a gente desenhasse no quadro, para verificar. Então, expliquei para as crianças que usaria "C" para representar as pessoas de cabelo curto e "L" para representar as pessoas de cabelo comprido/longo e propositalmente, organizei cinco linhas com dez pessoas em cada linha, já pensando em confrontar as hipóteses levantadas pelas crianças:

C L C L C L C L C L

C L C L C L C L C L

C L C L C L C L C L

C L C L C L C L C L

C L C L C L C L C L

Em seguida, começamos a numerar as pessoas representadas por letras, para verificar as hipóteses das crianças:

$\begin{array}{llllllllll}1 & 2 & 3 & 4 & 5 & 6 & 7 & 8 & 9 & 10 \\ \mathrm{C} & \mathrm{L} & \mathrm{C} & \mathrm{L} & \mathrm{C} & \mathrm{L} & \mathrm{C} & \mathrm{L} & \mathrm{C} & \mathrm{L} \\ 11 & 12 & 13 & 14 & 15 & 16 & 17 & 18 & 19 & 20 \\ \mathrm{C} & \mathrm{L} & \mathrm{C} & \mathrm{L} & \mathrm{C} & \mathrm{L} & \mathrm{C} & \mathrm{L} & \mathrm{C} & \mathrm{L} \\ 21 & 22 & 23 & 24 & 25 & 26 & 27 & 28 & 29 & 30 \\ \mathrm{C} & \mathrm{L} & \mathrm{C} & \mathrm{L} & \mathrm{C} & \mathrm{L} & \mathrm{C} & \mathrm{L} & \mathrm{C} & \mathrm{L} \\ 31 & 32 & 33 & 34 & 35 & 36 & 37 & 38 & 39 & 40 \\ \mathrm{C} & \mathrm{L} & \mathrm{C} & \mathrm{L} & \mathrm{C} & \mathrm{L} & \mathrm{C} & \mathrm{L} & \mathrm{C} & \mathrm{L} \\ 41 & 42 & 43 & 44 & 45 & 46 & 47 & 48 & 49 & 50 \\ \mathrm{C} & \mathrm{L} & \mathrm{C} & \mathrm{L} & \mathrm{C} & \mathrm{L} & \mathrm{C} & \mathrm{L} & \mathrm{C} & \mathrm{L}\end{array}$

Então, antes que eu terminasse de escrever os números até 50, algumas crianças já afirmaram: "Profe, todos os números que terminam com 1 tem cabelo curto e os que terminam com 2 , tem cabelo longo!" Então, aproveitei as afirmações das crianças e questionei: "E como é o cabelo das pessoas que estão nos números que terminam com 3?" Então me responderam que era curto. Então segui em meus questionamentos. "E dos números que terminam com 8?" "Ah, profe, são longos." Então questionei: “E que números são esses: 2, 4, 6 e 8?" "São os números de cabelo curtos, profe!", me responderam as crianças. Então pensei como poderia instigá-los mais e falei: “Tudo bem! E o 1, 3, 5, 7 e 9?" "Também profe! São os números de cabelo longos." Mas como eu queria que eles chegassem a conclusão que eram os números pares e os números ímpares, questionei mais uma vez: "Tudo bem, mas o que eles tem de especial? O que 2, 4, 6 e 8 tem de especial? Que tipo de números são o 1, 3, 5,7 e 9?” Então os alunos pensaram por alguns momentos, até que E3 e A3 disseram: "São os números pares e ímpares profe!" "Pares e ímpares?", questionei. Sim, me responderam os alunos. "E o que está acontecendo nesta sequência com os números pares? E com os números ímpares?" Questionei mais uma vez. As crianças pareciam não ter compreendido a questão. Então reformulei: "Como são os cabelos das pessoas, quando os números são pares? E quando são ímpares?" "Ah, profe! Nos números ímpares são curtos e nos pares, são longos!" "Que show!", eu disse e voltei a perguntar: "E o número 80, é par ou ímpar?" Hum, profe, termina em zero...deixa eu contar nos dedos (parece que aprenderam com a professora referência a intercalar par e ímpar nos dedos para definir qual número era par e qual era ímpar). "Deve ser par, pois o dez é par e termina em zero". Outro aluno disse também: "Deve ser par, porque vem antes do 1, e o um é ímpar." Então questionei: "Se o 80 é par, como será o comprimento do cabelo da pessoa que estiver na $80^{a}$ posição na fila?" "Ah, será longo, profe!” Responderam rapidamente. Então questionei: "E se fosse o 121?" E3 disse: "Hum, é ímpar, então será curto!"

Fonte: Diário de Campo (22 out. 2018). 
Observa-se nesta situação, que embora a proposta inicial era elencar o próximo termo ausente da sequência e em seguida elencar mais alguns elementos ausentes, os alunos conseguiram construir conjecturas, bem como utilizar o conceito de números pares e ímpares, estabelecendo relação destes com as sequências. Entende-se que isso foi possível, pois como sugere Boaler (2018), a atividade era de "piso baixo" e "teto alto", permitindo discussão, que partiu de um nível básico e se estendeu a um nível mais elevado. Aliás, esta proposta mostrouse rica em possibilidades, que uma delas acabou passando desapercebida pela pesquisadora no momento da interferência: A possibilidade de comparar duas ou mais sequências entre si e observar que "padrões construídos com materiais diferentes são realmente o mesmo padrão" (VAN DE WALLE, 2009, p. 296). Esta possibilidade de exploração foi constatada posteriormente, durante a tabulação de dados das atividades escritas propostas à turma.

Nas atividades escritas, primeiramente os alunos representaram em folhas de desenhos, as filas que foram criadas na brincadeira "Detetive". Esta atividade foi realizada em duplas, mas cada aluno tinha sua folha para desenhar. Em seguida, elaboraram uma "fila" a partir de seus próprios parâmetros e descreveram com suas palavras os critérios (padrões) utilizados na construção de suas representações. Ao tabular e analisar as respostas dos alunos posteriormente, foi possível observar que dos 17 alunos presentes, apenas um aluno do $2^{\circ}$ ano reproduziu uma sequência igual a realizada na brincadeira do "Detetive". Todos os demais criaram sequências e/ou padrões novos, tais como: "um triângulo, um círculo, um triângulo..." ou "um coração, uma estrela, um coração..." ou um triângulo, dois palitos, um triângulo..." ou ainda "uma árvore, dois corações, uma árvore..." De posse desses dados, foi possível concluir que os alunos compreenderam que o "núcleo de um padrão repetitivo é a menor cadeia de elementos que se repete" (VAN DE WALLE, 2009, p. 296, grifo do autor). Ademais, como já mencionado, a pesquisadora deixou escapar a oportunidade de comparar as sequências, como por exemplo, um triângulo, dois palitos, um triângulo..." e "uma árvore, dois corações, uma árvore..." estabelecendo relações entre elas. Se relacionarmos as sequências citadas com letras do alfabeto, como sugere Van de Walle (2009), teremos o padrão A-B-B-A-B-B para ambas as sequências, o que segundo o autor, seria um avanço significativo na aprendizagem. À vista disso, entende-se que seria adequado propiciar à turma, em outro momento, a comparação de padrões entre as sequências, visando avançar no processo de ensino e aprendizagem e estabelecer as relações sugeridas por Van de Walle (2009).

\subsection{Brincando com o Lego}

A atividade "Brincando com o Lego", que também oportunizava a construção de sequências mediante determinado padrão, foi realizada durante a terceira e quarta aulas constituindo-se como parte integrante da segunda interferência realizada pela pesquisadora junto à turma. A atividade pautava-se em criar sequências, identificar seus padrões e elementos ausentes, a partir de alguns critérios pré-estabelecidos pela pesquisadora, de forma lúdica. Exemplos do que foi proposto: 
a) Montar uma sequência com as peças de lego, utilizando duas cores a serem escolhidas pelos estudantes, intercalando de uma em uma as cores. Após a montagem da sequência, os estudantes realizaram a representação da mesma em folha de desenho, escrevendo o padrão da sequência com suas palavras.

b) Montar uma sequência com as peças de lego, utilizando duas cores a serem escolhidas pelos estudantes, intercalando duas peças de uma cor e uma peça de outra cor. Após a montagem da sequência, os estudantes realizaram a representação da mesma em folha de desenho, escrevendo o padrão da sequência com suas palavras. Através desta atividade, pretendia-se introduzir formalmente as terminologias de "padrão" e "sequência" à turma.

Após a realização da primeira proposta, a pesquisadora observou que todos os grupos estavam utilizando a mesma forma de representar as sequências. Estavam organizando uma peça ao lado da outra sobre a mesa, conforme exemplifica a Figura 1:

Figura 1 - Registro 1 da Proposta 1 da atividade "Brincando com Lego"

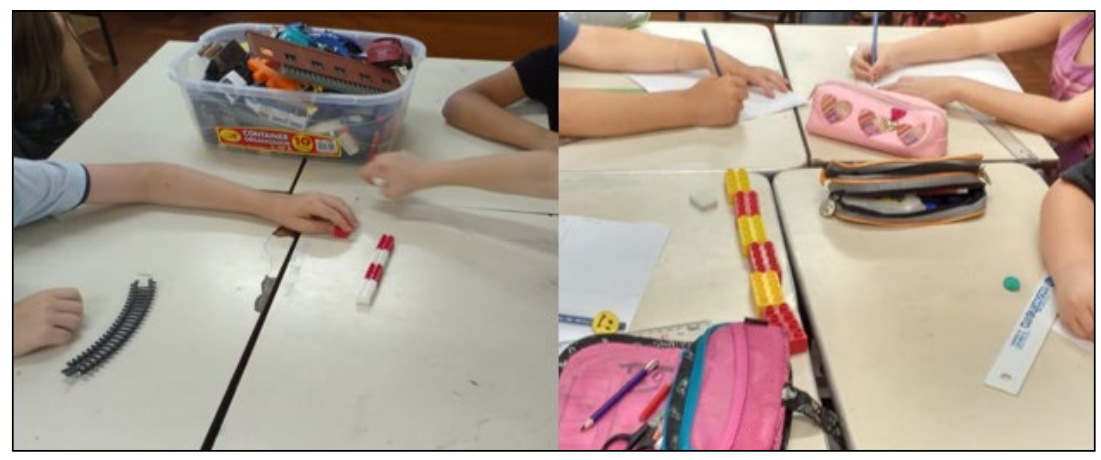

Fonte: Arquivo de Pesquisa (29 out. 2018).

Então, durante a proposta 2 da atividade Brincando com Lego, a pesquisadora achou pertinente questionar os alunos sobre a possibilidade de outras formas de organização, uma vez que um mesmo padrão poderia ser construído usando outras representações, de acordo com o que propõe Van de Walle (2009, p. 296). Foi possível perceber, que esta interferência qualificou as construções das crianças, pois as mesmas começaram a estabelecer relações entre duas sequências de mesmo padrão, mas com organizações de peças diferentes, conforme é possível vizualizar na Figura 2: 
Figura 2 - Registro 2 da Proposta 2 da atividade "Brincando com Lego"

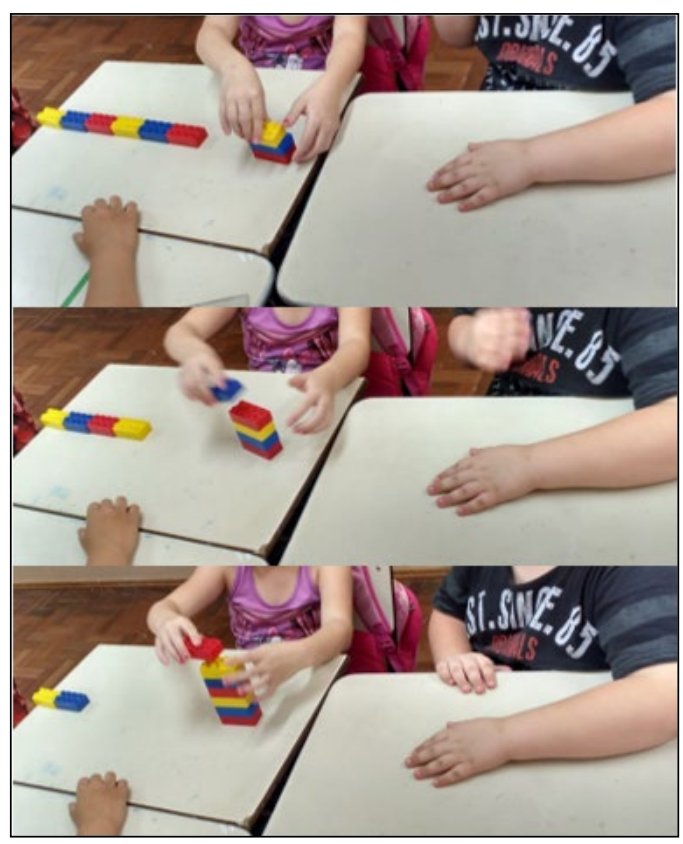

Fonte: Arquivo de Pesquisa (29 out. 2018).

É possível observar, na Figura 2, que as crianças fazem a modificação de uma sequência de peças que estão uma do lado da outra sobre a mesa, para uma sequência de peças em formato de pilha. Quando questionadas pela pesquisadora sobre qual seria o padrão da nova sequência, as crianças respondem que é o mesmo, pois apenas mudaram o jeito de arrumar as peças. Da análise desta situação, é possível concluir que as reflexões da pesquisadora quando do exame dos materiais coletados no primeiro encontro com a turma, permitiram que estas refletissem sobre o seu planejamento qualificando as suas intervenções no segundo encontro. Ou seja, a possibilidade de comparar duas ou mais sequências entre si e observar que "padrões construídos com materiais diferentes são realmente o mesmo padrão" (VAN DE WALLE, 2009, p. 296) desta vez não passou despercebida pela pesquisadora. Estas aproveitaram a oportunidade para potencializar os processos de ensino e aprendizagem da turma. Da mesma forma, é possível observar na Figura 3, outra representação que se destacou na turma: 
Figura 3 - Registro 3 da Proposta 2 da atividade "Brincando com Lego"

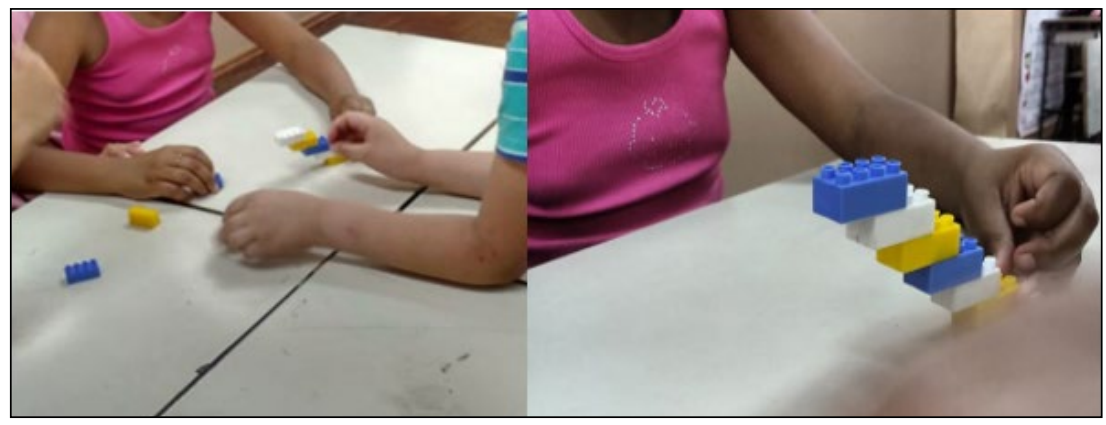

Fonte: Arquivo de Pesquisa (29 out. 2018).

Os alunos deste grupo, foram os únicos a elaborarem a alternativa "da escadinha", assim denominada por eles, para representar a sequência de mesmo padrão exemplificada na Figura 2. Embora esse não tenha sido o objetivo inicial da atividade, entende-se que a atividade contribuiu para o desenvolvimento do pensamento algébrico, pois permitiu a comparação entre padrões construídos com organizações diferentes (por exemplo, a pilha e a escadinha). Além disso, sabe-se que

A realização de investigações matemáticas proporciona, muitas vezes, o estabelecimento de conexões com outros conceitos matemáticos e até mesmo extramatemáticos. $\mathrm{O}$ professor precisa estar atento a tais oportunidades e, mesmo que não seja possível explorar cabalmente essas conexões, deve estimular os alunos a refletir sobre elas (PONTE; BROCARDO; OLIVEIRA, 2003, p. 51).

Portanto, mesmo que não tenha sido possível concluir todas as atividades previstas para este encontro, infere-se que as atividades realizadas tenham permitido aos alunos estabelecerem relações algébricas que não estavam previstas no planejamento e muito menos na BNCC (BRASIL, 2017) para estas turmas.

\subsection{Brincando e aprendendo com sequências}

A proposta desta terceira interferência, realizada durante a quinta, sexta, sétima e oitava aulas, era trabalhar o uso de padrões e sequências a partir de material impresso, diferentemente das primeiras duas interferências. À vista disso, num primeiro momento, a aplicadora optou por realizar um momento de retomada de ideias já previsto e em seguida, entregar o material impresso para que os alunos tentassem respondê-lo de forma autônoma, em duplas. O material impresso continha sequências figurais e questionamentos referentes a estas sequências. Os questionamentos demandavam que os alunos elencassem os próximos elementos da sequência, determinassem o padrão ou "regra" da sequência ou ainda, determinassem algum elemento que estivesse na "n" posição da sequência. Observou-se, no entanto, durante o desenvolvimento desta proposta, que muitos 
alunos estavam com dificuldades para ler, compreender e responder as atividades propostas, mesmo atuando em duplas e com interferências da pesquisadora (QUADRO 5). Isto posto, após certo tempo de interação dos alunos com o material impresso, algumas questões respondidas e constatada dificuldades de leitura e interpretação, optou-se pela leitura coletiva e pela socialização das respostas que já haviam sido elaboradas pelos alunos para dar continuidade ao trabalho. Esta forma de interação levou em consideração as ponderações de Ponte, Brocardo e Oliveira (2003, p. 26) ao afirmarem que "no caso de alunos mais novos, a leitura conjunta do enunciado poderá ser imprescindível para a sua boa compreensão, nem que seja somente para esclarecer certos termos com que não estão familiarizados". Acresce que, Ponte, Brocardo e Oliveira (2003, p. 25) asseveram que a "discussão dos resultados, em que os alunos relatam aos colegas o trabalho realizado" é uma etapa importante, pois neste momento há trocas de experiências e discussão de resultados/estratégias diferentes, assim como, a análise construtiva dos erros.

Quadro 5 - Brincando e aprendendo com sequências - Trecho I.

Observei que a realização da leitura coletiva foi importante para a realização das atividades
propostas, pois muitos dos alunos que deixaram de fazê-la, o fizeram devido a sua dificuldade de
leitura e escrita, em especial os alunos do $2^{\circ}$ ano. Neste sentido, considero que seja pertinente numa
outra oportunidade pensar em reagrupamentos diferentes, onde ao menos um dos alunos seja um
leitor fluente, favorecendo assim o processo de leitura e interpretação das questões, viabilizando
maior fluidez na realização das atividades. Junto a isso, constatei que embora soubessem verbalizar
as respostas das atividades, em especial os alunos do segundo ano, apresentaram dificuldades
para escrevê-las. Processo este, que por fim optei por realizar no quadro, atuando como escriba
daqueles que apresentavam esta necessidade.

Fonte: Diário de Campo (19 nov. 2018).

Desta forma, manteve-se os alunos em duplas e combinou-se com eles, que coletivamente seria feita a leitura de cada questão, que haveria a disponibilidade de um curto tempo para construírem ou reverem a resposta já esboçada e logo em seguida, apresentá-la ao grande grupo. Observa-se, pelas anotações do Diário de Campo, expostas no Quadro 5, que esta alternativa foi pertinente. Nesta situação Ponte, Brocardo e Oliveira (2003, p. 30), explicam que "a situação de trabalho em grupo potencializa o surgimento de várias alternativas para a exploração da tarefa".

Já na atividade 2, apresentada nas Figuras 4 e 5, os alunos foram provocados através dos seguintes questionamentos: "Qual é o padrão dessa sequência? Como deve ser colocado o próximo palito da sequência? Como deverá ser colocado o $24^{\circ}$ palito da sequência? Como você descobriu isso? Como deverá ser colocado o $28^{\circ}$ palito da sequência? Como você descobriu isso? Como deverá ser colocado o $41^{\circ}$ palito da sequência? Como você descobriu isso?" Essas provocações, durante o desenvolvimento dessa atividade (FIGURAS 4 e 5, QUADROS 6 e 7), permitiram aos alunos a possibilidade de construir padrões e sequências diferentes para uma mesma questão, ampliando o leque de discussões e potencializando as argumentações destes acerca de suas respostas. 
Figura 4 - Brincando e aprendendo com sequências - Aluno E3.

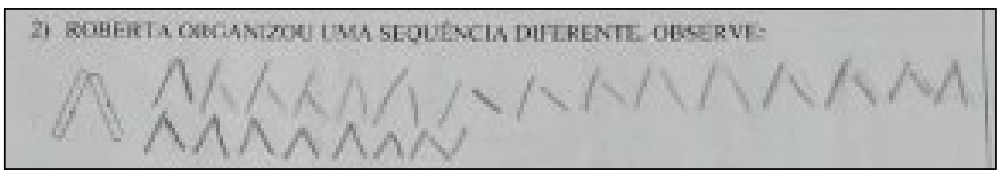

Fonte: Arquivo de Pesquisa (19 nov. 2018).

Observa-se nestas figuras, que ambos os alunos fizeram uso de padrões repetitivos, onde o "núcleo é sempre completamente repetido e nunca apenas parcialmente mostrado" (VAN DE WALLE, 2009, p. 296). No entanto, os núcleos criados pelos alunos foram diferentes. $\mathrm{Na}$ figura 4, observamos que o aluno E3 optou por repetir a organização de palitos que já estava posta na atividade. $\mathrm{O}$ aluno D3 (FIGURA 5), por sua vez, optou por ampliar o núcleo de seu padrão, acrescendo novos elementos a ele. Essas observações são validades pelas descrições apresentadas por esses alunos nos Quadros 6 e 7.

Figura 5 - Brincando e aprendendo com sequências - Aluno D3.

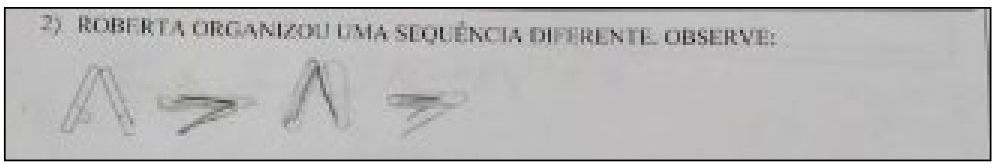

Fonte: Arquivo de Pesquisa (19 nov. 2018).

Ou seja, mesmo atuando em grupos e fazendo discussões coletivas na turma, os alunos apresentaram hipóteses diferentes para a mesma questão, o que enriqueceu as discussões e demonstrou desenvolvimento do pensamento algébrico por parte destes, conforme podemos observar nos Quadros 6 e 7. Ressalta-se desta forma que " os momentos de trabalho autônomo em pares possibilitam aos alunos progredir na interpretação da situação e na procura de respostas e discutir de modo detalhado várias possibilidades" (PONTE et al., 2017, p. 249).

Quadro 6 - Transcrição das respostas do aluno E3 para a atividade 2

Pergunta: QUAL É O PADRÃO DESSA SEQUÊNCIA?

Resposta: 1 enclinado para a direita e um para a esquerda

Pergunta: COMO DEVERÁ SER COLOCADO O PRÓXIMO PALITO DA SEQUÊNCIA?

Resposta: 1 enclinado para a direita

Pergunta: COMO DEVERÁ SER COLOCADO O $24^{\circ}$ PALITO DA SEQUÊNCIA? COMO VOCÊ DESCOBRIU ISSO?

Resposta: 1 enclinado para a esquerda, desenhando

Pergunta: COMO DEVERÁ SER COLOCADO O $28^{\circ}$ PALITO DA SEQUÊNCIA? COMO VOCÊ DESCOBRIU ISSO?

Resposta: 1 enclinado para a esquerda, desenhando

Fonte: Diário de Campo (19 nov. 2018). 
Observa-se ainda nos Quadros 6 e 7, que os alunos voltam a fazer uso das relações recursivas para elencarem a posição de determinado palito na sequência. Infere-se desta situação, que durante o desenvolvimento do pensamento algébrico, os alunos ora estabelecem relações recursivas, ora estabelecem relações funcionais, intercalando-as conforme o contexto em que estão inseridos.

Quadro 7 - Transcrição das respostas do aluno D3 para a atividade 2

Pergunta: QUAL É O PADRÃO DESSA SEQUÊNCIA?
Resposta: dois palitos em forma de um A e dois palitos em forma de um A deitado
Pergunta: COMO DEVERÁ SER COLOCADO O PRÓXIMO PALITO DA SEQUENNCIA?
Resposta: dois palitos em forma de um A
Pergunta: COMO DEVERÁ SER COLOCADO O $24^{\circ}$ PALITO DA SEQUÊNCIA? COMO
VOCÊ DESCOBRIU ISSO?
Resposta: em forma de um A em pé. Eu sei por que ue contei na minha cabeça
Pergunta: COMO DEVERÁ SER COLOCADO O $28^{\circ}$ PALITO DA SEQUENNCIA? COMO
VOCÊ DESCOBRIU ISSO?
Resposta: em forma de um A de em pé. Eu sei por que eu contei na minha mente.

Fonte: Diário de Campo (19 nov. 2018).

Junto a isso, é possível observar pelas respostas dos alunos nos Quadro 6e 7, que a socialização permitiu a alguns alunos refletirem sobre suas próprias ações e a estabelecerem novas conjecturas, que num primeiro momento não haviam sido pensadas.

A apresentação de estratégias é importante para os alunos compreenderem as situações segundo diferentes perspectivas, esclarecerem significados e perceberem a importância do uso de representações eficientes. Esta apresentação cria também as condições para que os alunos possam fazer uma posterior generalização (PONTE, et al. 2017, p. 240).

Observa-se aqui novamente um ponto em comum com a investigação matemática descrita por Ponte, Brocardo e Oliveira (2003): a discussão de resultados, apresentada pelos autores como a última fase deste processo.

\subsection{Sequências numéricas}

A última intervenção na turma, ocorrida na nona e décima aulas, previa o trabalho com sequências numéricas. As atividades foram organizadas com o objetivo de identificar seus padrões e elementos ausentes, assim como, aprofundar o uso das terminologias "padrão" e "sequência" apresentados à turma anteriormente. Observa-se pelo Quadro 8, que embora as crianças tenham compreendido de forma intuitiva o que são sequências e padrões, a utilização da nomenclatura ainda é um obstáculo a ser superado pela maioria dos alunos e explicita a necessidade de novas intervenções neste sentido. 
Quadro 8-Sequências numéricas - Trecho I.

Inicialmente retomei com a turma as noções de sequência e padrão. Percebi que os alunos compreenderam o que é uma sequência, mas que ainda estão com dificuldades para lidar com a nomenclatura "padrão". Ao serem questionados oralmente sobre o padrão de uma sequência, muitos apresentam dúvidas. No entanto, assim que realizei interferências fazendo alusão a brincadeira de detetive, realizada no primeiro dia de intervenção, ou questionando qual a "regra" usada para montar aquela sequência, rapidamente a turma conseguia responder. Penso que este deve ser um ponto de ajuste na atividade e que talvez em uma próxima oportunidade, deva usar algo como "a lei de formação" ou "a regra de formação" para me referir aos padrões que desejo que os alunos identifiquem na sequência. Considero ainda, que isso também possa estar ocorrendo devido ao curto período de intervenções realizadas e ao fato dos alunos terem seu primeiro contato com esta nomenclatura nestas intervenções.

Fonte: Diário de Campo (26 nov. 2018).

Além disso, esta interferência permitiu inferir algumas hipóteses criadas pelos alunos para elencar os elementos ausentes de uma sequência numérica e trabalhar com o conceito de infinito (que não era o objetivo desta atividade), conforme se observa no Quadro 9. Historicamente o conceito de infinito vem sendo discutido no campo da matemática, causando estranhezas e inquietações. Ele

[...] foi o maior responsável pelas duas grandes crises nos fundamentos desta ciência e, ainda hoje, causa certo desconforto devido à sua natureza paradoxal. Foi pelos caminhos dos paradoxos que o conceito de infinito se desenvolveu e ainda hoje consiste num terreno fértil para pesquisas na área de Educação Matemática (PIMENTEL; SANTOS; MOMETTT, 2010, p. 53).

Logo, deduz-se que o trabalho com sequências e padrões oportuniza, já nos Anos Iniciais, a reflexão sobre um conceito importante, complexo e paradoxal no campo da matemática, o conceito de infinito. A noção de infinito, observada no Quadro 9, aproxima-se da ideia de infinito potencial, que segundo Pimentel, Santos e Mometti (2010, p. 55) se caracteriza pelo pensar que "é sempre possível acrescentar mais um algarismo [...] e que este processo nunca termina". 


\section{Quadro 9-Sequências numéricas - Trecho II.}

Após a leitura do texto, pedi que os alunos respondessem as duas questões da letra $\mathrm{A}$ de forma individual e posteriormente, realizei alguns questionamentos orais. Escrevi a sequência da alternativa A no quadro $(2-4-6-8-10-12 \ldots)$ e questionei: "Quem é o próximo número da sequência?" Ao passo que alguns responderam 14 e outros 2. Questionei os que responderam 2 , o motivo de suas respostas. Me disseram que acharam que a sequência se repetia, por isso usaram o 2 novamente. Os que responderam 14, disseram que é por que a sequência aumentava e mudava de $2 \mathrm{em} 2$ ou ainda, porque pulava um número. Em seguida questionei o motivo pelo qual haviam três pontinhos no final da sequência. Os alunos rapidamente responderam que foi porque a sequência continuava. Então pedi até que número a sequência continuava já visando testar a noção de infinito dos alunos. Daí um disse 30. Outro disse: "Não, 50 profe." Então questionei: "E se eu quiser escrever até 120, posso?" Alguns ficaram na dúvida, mas a maioria concordou que sim. Então questionei do porquê. E juntos fomos analisar a sequência. Os alunos me disseram que poderia somar dois, e assim fui fazendo o registro no quadro, para que todos visualizassem. Então montamos mais alguns termos da sequência. Novamente questionei os alunos: "Posso escrever valores maiores que 120 nessa sequência?” Daí eles me disseram que sim. Questionei quais. Eles me disseram outros ainda mais altos até que de repente uma aluna disse: "Profe, essa sequência é infinita!" Então eu disse: "Infinita???? Mas o que é ser infinita?" Ela respondeu: "É continuar escrevendo sem parar!” Daí outro colega contribuiu: "Sempre dá para escrever mais um, profe!"

Fonte: Diário de Campo (26 nov. 2018).

Além disso, é possível observar no Quadro 9 e no Quadro 10, que ao serem questionados sobre os próximos termos da sequência ou sobre os termos ausentes, os alunos fizeram uso de relações recursivas (VAN DE WALLE, 2009). Ou seja, quando os alunos disseram que somavam dois ao último termo para conhecer o próximo (QUADRO 9), ou ainda, que somavam três ao último termo para conhecer o próximo (QUADRO 10), estavam utilizando como recurso, o termo anterior, para construir o termo seguinte, sem estabelecer uma regra ou norma para determinar um termo qualquer da sequência.

\section{Quadro 10 - Sequências numéricas - Trecho III.}

Em seguida, observei que os alunos tinham facilidade para descrever oralmente o padrão da sequência, mas que estavam apresentando dificuldades para responder à pergunta: "O que você observa nessa sequência". O que me fez pensar em duas possibilidades: a dificuldade de leitura e interpretação já mencionada pela professora e a necessidade de uma reelaboração da questão. $\mathrm{Na}$ atividade $\mathrm{B}$, observei as mesmas dificuldades, embora a atividade fosse um pouco diferente e tivesse objetivos diferentes. Ao se referir ao padrão de sequência, novamente alguns alunos apresentaram dificuldades para interpretar a questão, ao passo que outros já a resolveram com maior habilidade. Também confundiram o número faltante com o próximo da sequência. Acredito que isso se deve em partes, por ainda não terem trabalhado este tipo de questão, mas em parte também pela dificuldade de interpretação da questão. Ao realizar intervenções no quadro, a grande maioria da turma soube me indicar que a sequência se modificava de $3 \mathrm{em} 3$, ou ainda, que bastava somar três para obter o próximo número. Ao questionar se era uma sequência de números pares ou ímpares, num primeiro impulso, alguns alunos disseram ser pares e outros ímpares, mas rapidamente os colegas já argumentaram que a sequência tinha os dois casos e, portanto, não era nem par e nem ímpar. No entanto, no final da aula, E3 me chamou para dizer que a sequência tinha uma regra: era um par, um ímpar, um par, um ímpar $(0-3-6-9-12 \ldots)$.

Fonte: Diário de Campo (26 nov. 2018). 
Por outro lado, é possível observar no Quadro 11, que os alunos foram além em suas estratégias ao fazerem a relação entre dois termos da sequência ${ }^{1}\left(5^{\circ}\right.$ e $10^{\circ}$ termo) e perceberem que os somando, poderiam encontrar o termo desconhecido $\left(15^{\circ}\right.$ termo). Esta relação estabelecida pela aluna F2 se aproxima de uma relação funcional (VAN DE WALLE, 2009). Isto já havia ocorrido em outros momentos, como por exemplo, quando os alunos estabeleceram a relação de ímpar/par, no Quadro 4.

Quadro 11 - Sequências numéricas - Trecho IV.

Para o $15^{\circ}$ termo surgiu mais uma hipótese. Como a sequência já estava exposta até o $10^{\circ}$ termo no quadro, a aluna F2 disse: "Basta somar dez e cinco (referindo-se a posição dos termos) vai dar 170, profe.” Então questionei ela sobre o que seria somar 10 e 5, pois eu queria que ela explicasse ao restante do grupo. Ao passo que ela respondeu, segura de si: "Ora, profe, já sei que o 10 é 120 (Fazendo alusão ao $10^{\circ}$ termo da sequência) e que o 5 é 70 (Fazendo alusão ao $5^{\circ}$ termo da sequência), então juntando os dois, vai dar 190". Outros disseram que foram contando até chegar a 170. Teve ainda os que escreveram a sequência até chegarem no termo desejado.

Fonte: Diário de Campo (26 nov. 2018).

Por outro lado, para Van de Walle (2009, p. 294), os alunos, ao tentarem provar suas conjecturas, podem cair em três categorias: a autoridade, o uso de exemplos e a lógica, em forma ascendente de complexidade. Ora, tanto no Quadro 11 como no Quadro 12, pode-se identificar duas dessas categorias. Ao relatarem que escreveram a sequência para identificar o termo ausente, de certa forma os alunos estavam fazendo uso de exemplos para provarem suas conjecturas, pois estavam testando um a um os elementos da sequência, até chegarem ao termo desejado. Esta categoria (uso de exemplos), segundo Van de Walle (2009, p. 294) se caracteriza pela "experimentação de muitos números específicos em uma conjectura". E ao criarem certas regras para determinarem os elementos ausentes, os alunos estavam fazendo uso da lógica, a categoria considerada mais complexa por Van de Walle (2009, p. 294).

1 A sequência que estava sendo explorada era $30-40-50-60-70 \ldots$ E os questionamentos realizados nesta atividade eram: Quem será o próximo termo da sequência? Qual o padrão da sequência? Quem será o $10^{\circ}$ termo da sequência? Como você fez para descobrir o $10^{\circ}$ termo da sequência? 
Em relação a atividade $D$, que apresentava a sequência " $6-12$..." e questionava quais números estavam faltando na sequência, solicitando que os alunos escrevessem os quatro próximos termos e descrevessem o padrão da sequência penso ser necessário revê-la. Esta atividade, foi a que se apresentou com mais dificuldades de interpretação e penso que foi falha na elaboração da mesma. No entanto, os alunos puderam realizar múltiplas interpretações desta atividade. Quando questionei os números que estavam faltando na sequência, alguns alunos me pediram ajuda angustiados, pois disseram que não tinha como colocar todos os números que estavam faltando, pois a sequência era muito grande, infinita... Outros, por conta própria escreveram alguns termos da sequência e colocaram reticências e um aluno escreveu apenas o 18. Em seguida, ao serem questionados sobre como deveriam escrever os quatro próximos números da sequência, os alunos ficaram em dúvida se deveriam ser considerados os termos a partir dos dois termos já expostos $(6-12 \ldots)$ ou se deveriam continuar de onde tinham parado na questão anterior. Consideramos as duas possibilidades como corretas e as respostas da turma se alternaram entre elas. Por fim, ao serem questionados sobre o padrão da sequência, a maioria relatou que mudava de seis em seis, sendo que uma aluna disse desta vez, ter utilizado o cartaz dos números para achar a resposta.

Fonte: Diário de Campo (26 nov. 2018).

Analisando ainda as narrativas do Quadro 12, é possível constatar que novamente a temática infinito se faz presente neste contexto, assim como as relações recursivas e funcionais estabelecidas pelos alunos no decorrer da resolução das atividades propostas. Estas reflexões e relações, ocorreram, em parte, pela intervenção da pesquisadora que vão ao encontro dos estudos de Brodie (2010 apud PONTE et al., 2017) relatados por Ponte et al. (2017) sobre a ação do professor. Ponte et al. (2017, p. 147, grifo do autor), a partir de seus estudos, evidencia "dois tipos de intervenções que podem servir para promover ou estender o raciocínio matemático dos alunos: questionar, em que o professor procura obter deles nova informação, e pressionar (press), em que procura levá-los a elaborar ou reforçar as suas ideias".

Por outro lado, as considerações da aplicadora, expostas no Quadro 12, sobre a possível necessidade de readequação da atividade, remetem ao processo de reflexão, o que indica mais uma aproximação com as etapas da investigação matemática conceituada por Ponte, Brocardo e Oliveira (2003). Encerra-se, dessa forma, parcialmente as ponderações sobre o presente contexto de investigação, haja visto que a pesquisadora tem clareza que outras argumentações ainda poderiam ser feitas.

\section{Consideraçóes Finais}

O desenvolvimento de atividades sobre padrões e sequências, junto a uma turma aglutinada dos Anos Iniciais do Ensino Fundamental, permitiu observar que as atividades desenvolvidas, favoreceram o trabalho com esta turma, visto que permitiam uma ampla variedade de respostas. Além disso, as atividades propostas, propiciaram o desenvolvimento da autonomia, a estruturação de conceitos matemáticos que não estavam previstos na sequência de atividades desenvolvidas 
e a construção do pensamento algébrico, a partir da enumeração de hipóteses, que foram se modificando, na medida que as atividades avançavam.

No tocante a estruturação de conceitos matemáticos que não estavam previstos, foi possível observar que os alunos construíram e discutiram elementos sobre o conceito de infinito e sobre os números pares e ímpares, ultrapassando assim questões de pensamento algébricos que foram o objetivo inicial deste estudo.

No que se refere ao desenvolvimento do pensamento algébrico, foi possível constatar que o uso de sequências e padrões permitiu a formação da noção de núcleo de um padrão repetitivo e a construção de relações recursivas e funcionais. Salientase que estas relações ocorreram mediante as provocações realizadas no decorrer das atividades, que visavam comparar e analisar as hipóteses apresentadas pelos alunos. Ou seja, o uso de sequências e padrões propiciou o desenvolvimento do pensamento algébrico nestes alunos, ampliando de forma rizomática a construção e discussão de outros conceitos não previstos inicialmente e que necessariamente não precisam ser do campo algébrico.

Constatou-se ainda, que a turma do segundo ano apresentou maior dificuldade para sistematizar suas hipóteses em forma escrita, o que pode ser atribuído ao fato dos alunos ainda não estarem com o processo de alfabetização finalizado. Além do mais, entende-se que o hábito do registro e da sistematização, precisa ser construído com os alunos, como indica Ponte, Brocardo e Oliveira (2003). Portanto, observase que esta curta inferência de apenas dez períodos provavelmente não seja tempo suficiente para que todos os alunos se apropriem desta prática de sistematização.

Ademais, percebeu-se que algumas atividades poderiam ter suas questões reformuladas, a fim de potencializar o processo de aprendizagem, permitindo maior autonomia às crianças e maiores hipóteses de investigação. Entre elas poderíamos citar, por exemplo, a modificação da questão em que primeiramente se solicitava para que as crianças desenhassem uma sequência e em seguida fizessem questionamentos a respeito dela. A ordem utilizada na atividade logo após a construção do desenho da sequência foi "Agora que sua sequência está pronta, escreva algumas perguntas para desafiar seus colegas". Diante desta atividade, B3 elencou como uma de suas questões: "Você tem medo de escuro?" O que nos indica que para esta criança não ficou claro que a questão proposta estava relacionada com a questão anterior de criação de sequência. Quando questionada sobre o motivo pelo qual B3 tinha elencada essa pergunta, esta respondeu que foi porque a ordem mandava criar perguntas para desafiar os colegas. E, para B3, falar sobre o escuro era um desafio, o que é compreensível para essa faixa etária. Diante disso, uma nova explicação se fez necessária o que resultou na seguinte fala de B3: "Mas porque você não falou logo que era sobre o desenho?" Esta fala de B3 indica a necessidade de reescrita da questão. Uma possibilidade seria reescrever a questão da seguinte forma: "Agora que sua sequência está pronta, escreva algumas perguntas sobre ela para desafiar seus colegas".

Em vista disso, conclui-se que as atividades envolvendo sequências e padrões contribuíram para o desenvolvimento do pensamento algébrico dos alunos alvo 
de aplicação destas, mas que devem ser suscetíveis à reflexão e reformulação. Por outro lado, constatou-se que as habilidades propostas pela BNCC (2017) a que este trabalho se propôs a explorar foram atingidas por grande parte dos alunos, demonstrando a viabilidade de se colocar em prática o que a BNCC (2017) propõe sobre o campo da álgebra para as turmas de segundo e terceiro ano.

\section{Referências}

BRASIL. LDB: Lei de diretrizes e bases da educação nacional. Brasília: Senado Federal, Coordenação de Edições Técnicas, 2018. Disponível em:< http://www2.senado. leg.br/bdsf/bitstream/handle/id/544283/lei_de_diretrizes_e_bases_2ed.pdf $>$ Acesso em: 15 abr. 2019.

BRASIL. Secretaria de Educação Fundamental. Parâmetros curriculares nacionais: matemática. Brasília: MEC/SEF, 1997. Disponível em: <http://portal.mec.gov.br/seb/ arquivos/pdf/livro03.pdf> Acesso em: 16 ago. 2018.

BRASIL. Ministério da Educação. Base Nacional Curricular Comum. Disponível em: $<$ http://basenacionalcomum.mec.gov.br/wp-content/uploads/2018/02/bncc-20dezsite.pdf> Acesso em: 16 ago. 2018.

BOALER, J. Mentalidades matemáticas: estimulando o potencial dos estudantes por meio da matemática criativa, das mensagens inspiradoras e do ensino inovador. Tradução: Daniel Bueno. Porto Alegre: Penso, 2018.

GERHARDT, T. E.; SILVEIRA, D. T. (orgs.). Métodos de pesquisa. Porto Alegre: Editora da UFRGS, 2009.

GIL, A. C. Métodos e técnicas de pesquisa social. 6. ed. São Paulo: Atlas, 2012.

MESTRE, C. M. M. V. O desenvolvimento do pensamento algébrico de alunos do $4^{\circ}$ ano de escolaridade: uma experiência de ensino. 379f. Tese. Doutorado em Educação Didática da Matemática. Instituição de Ensino: Universidade de Lisboa, Lisboa, 2014. Disponível em: < http://repositorio.ul.pt/bitstream/10451/15481/1/ulsd069340_ td_Celia_Mestre.pdf> Acesso em: 01 out. 2018.

MICHEL, M. H. Metodologia e pesquisa científica em ciências sociais: um guia prático para acompanhamento da disciplina de elaboração de trabalhos monográficos. 3 . ed. São Paulo: Atlas, 2015.

PONTE, J. P. da; BROCARDO, J.; OLIVEIRA, H. Investigações Matemáticas na Sala de Aula. Belo Horizonte: Autêntica, 2003.

PONTE, J. P. et al. Investigações matemáticas e investigações na prática profissional. São Paulo: Editora Livraria da Física, 2017.

SMOLE, K. S. Jogos de matemática de $\mathbf{6}^{\circ}$ ao $\mathbf{9}^{\circ}$ ano. Porto Alegre: Artmed, 2009.

VAN DE WALLE, J. A. Matemática no ensino fundamental: formação de professores e aplicação em sala de aula. Tradução: Paulo Henrique Colonese. Porto Alegre: Artmed, 2009. 